\title{
Pooled Preventive Behaviors'for Main Chronic Non-Communicable Diseases as a Double Burden of Public Health among Healthcare Students, Southwest Ethiopia
}

Teklemichael Gebru*

Department of Public Health, Health Science and Medicine, Wolkite University, Wolkite, Ethiopia

\section{Abstract}

Background: Non-communicable chronic disease is a life-treating disease that can be prevented but not cured. Reducing risks, promoting healthy life at early age reduces the burden of chronic diseases currently account for almost $60 \%$ of all deaths and $43 \%$ of the global burden of disease. As a result of an epidemiological transition attributed to increased urbanization, westernization, and globalization, many African countries are experiencing lifestyle change that results a "double burden" alongside to infectious diseases. Cardiovascular diseases, cancer, chronic obstructive pulmonary disease and type two diabetes are the most four prominent chronic diseases globally.

Objective: To assess preventive behavior for main chronic diseases among Aman healthcare students.

Methods: A cross-sectional study design was employed in May 2015 at Aman Health Science College using health belief model. A stratified sampling technique was used to select 267 students. An adapted self-administered questioner and calibrated measuring scale were used to collect data. A summery descriptive and, binary and multivariate logistic regression was applied to describe the functional predictors of preventive behavior. Ethical clearance of the study was obtained from institutional review committee.

Result: Majority of the study participants $190(73.9 \%)$ were females and the mean age was 20.24 year $( \pm 2.42$ SD). Majority of the respondent $214(83.3 \%)$ were centrally obese. Independent predictor of preventive behavior for chronic disease were being college stay $3^{\text {rd }}$ year [OR: $\left.2.06,95 \% \mathrm{Cl}:(1 \cdot 08,3.94)\right]$, being educated about chronic disease [OR: $2 \cdot 99,95 \% \mathrm{Cl}:(1 \cdot 64,5 \cdot 45)]$, and perceived susceptibility and severity to chronic disease [OR: $2 \cdot 97,95 \%$ $\mathrm{Cl}:(2 \cdot 04,5 \cdot 38)]$, and [OR: $2 \cdot 00,95 \% \mathrm{Cl}:(1 \cdot 12,3 \cdot 57)]$, respectively.

Conclusion: the disparity level of preventive behavior for chronic disease was well explained by knowledge and perceived threat. Cognizant of this fact, I recommend that integrated behavioral change communication education emphasized on perceived treat should be strengthening to reduce the burden of life-treating chronic diseases.

Keywords: Chronic disease; Preventive behavior; Healthcare student

\section{Background}

Non-communicable Chronic Disease (NCD) is a long-lasting disease that can be prevented but not cured, that leading to death and disability. The rates of NCDs are accelerating worldwide across every region and encompass all socioeconomic classes. Cardiovascular diseases (CVD), cancer, chronic obstructive pulmonary disease and type two diabetes are the most four prominent non-communicable chronic diseases globally [1,2]. According to World health report 2012; reducing risks and promoting healthy life reduces the burden of mortality, morbidity and disability attributed to chronic diseases currently shares for almost $60 \%$ of all deaths and $43 \%$ of disease globally [3]. By 2020 their contribution is expected to increase to $73 \%$ of all deaths and $60 \%$ of disease. Moreover, $79 \%$ of the deaths attributed to these diseases occur in the developing countries, which constitute a "double burden" alongside to infectious diseases. As a result of an epidemiological transition attributed to raised urbanization, westernization, and globalization, many sub-Saharan African countries are experiencing lifestyle and behavioral changes in populations.

Even though, most of non-communicable chronic diseases are considered as diseases of elderly age, researchers have suggested starting chronic disease risk factors prevention programs among youth age is crucial to reduce chronic disease related morbidity, disability and mortality later in life [4], For instance studies done among university and college students found that are at risk of developing chronic disease like heart diseases [5]. The college year represent a major transition for students' behavior because they are living away from home for the first time and have to make lifestyle decisions regarding personal health without their parents. Students begin adopting unhealthy behaviors like binge drinking, smoking, and poor dietary choices [6]. Thus, college setting offers an excellent platform to study preventive behavior for chronic disease particularly Cardiovascular Disease (CVD), hypertension and diabetes mellitus [7].

These prominent chronic disease shares a few common risk factors like high blood pressure and cholesterol level, tobacco use, excessive alcohol use, inadequate intake of fruit and vegetables, and being overweight, obese or physically inactive, all of diet and behavior related conditions are on the rise in many African countries [8]. Therefore, in this study preventive behavior for these chronic disease (able to prevent) is defined as: if an individual is not smoking cigarette and $\leq 2$ alcohol consuming, and if individual is taking adequate fruit/vegetable for at least five servings per day and consistently doing physical exercise

*Corresponding author: Teklemichael Gebru, Department of Public Health, Health Science and Medicine, Wolkite University, Wolkite, Ethiopia, Tel: 0911855199 E-mail: teklemichaelgebru@gmail.com

Received December 19, 2015; Accepted December 30, 2015; Published January 06, 2016

Citation: Gebru T (2016) Pooled Preventive Behaviors' for Main Chronic NonCommunicable Diseases as a Double Burden of Public Health among Healthcare Students, Southwest Ethiopia. J Trop Dis 4: 198. doi:10.4172/2329-891X.1000198

Copyright: (C) 2016 Gebru T. This is an open-access article distributed under the terms of the Creative Commons Attribution License, which permits unrestricted use, distribution, and reproduction in any medium, provided the original author and source are credited. 
for $\geq 30$ minutes/day [9-13].

Particularly, there is no documented evidence on chronic disease preventive behavior in the country. Therefore, this study aimed to assess preventive behavior on main chronic diseases cardiovascular disease, hypertension and type two diabetes mellitus among health science college students.

\section{Method and Subjects}

A cross-sectional study design was conducted from May 1 to 31 , 2015 at Aman health science college, Southwest Ethiopia. The college was established in 2005/6 as one of the four governmental health science colleges in South Nation Nationality People's Region (SNNPR) of Ethiopia. It is found in the Southwest part of Ethiopia, $561 \mathrm{~km}$ away from the country's capital city Addis Ababa. During the study period the college trains for about 659 students in different departments; clinical nursing, midwifery nursing, health extension, health information technique and medical laboratory technicians.

In this study Health Belief Model (HBM) theoretical framework was used to examine student motivations for adapting a health-related behavior. The HBM includes six key domains which influence health behaviors; perceived susceptibility, perceived severity, perceived benefits, perceived barriers, cues to action and self-efficacy. Perceived susceptibility addresses student's beliefs about their risk for getting chronic disease; whereas perceived severity relates to the student's concern about seriousness of these diseases. Perceived benefits are related to the outcomes of a certain behavior to reduce their susceptibility to or severity of these diseases. Perceived barriers identify student's concern or negative beliefs about health behavior. Cues to action are strategies or information sources that promote adoption of a behavior. Self-efficacy measures the student's confidence to adopt a behavior or to take action. Thus, the HBM has been used extensively to identify preventive perceptions and practices for chronic disease.

Sample size was calculated using Epi info version 7 by considering the following assumptions: the proportion of chronic disease preventive behavior was previously unknown, 50\% prevalence was used (as outcome variable), $5 \%$ margin of error, $95 \%$ confidence interval with corrections for finite population and $90 \%$ expected response rate. Accordingly, the required optimal sample size was 267 students.

A stratified sampling procedure was employed to select study participants. All students were stratified by their educational stay in the college as first, second and third year assuming that; knowledge of student varies with their duration of academic year that leads to variation of chronic disease preventive behavior. Then, the planned sample sizes were allocated proportional to size to all stratums (college stay). Finally, study units were selected using random number generator from the sampling frame of their identification number.

An adapted self-administered, pre-coded and pre-tested structured questionnaire and calibrated height and weight measuring scale were used to collect necessary data. The instrument includes demographic characteristics, knowledge, health belief model construct items, and preventive behavior practices such as alcoholism, physical exercise habit, and diet preference.

A double data entry was prepared using Epi-data $3 \cdot 1$ and then analyzed using SPSS version 20.0 statistical software. A principal component analysis was used to reduce knowledge related items with suitability for factor analysis $\mathrm{KMO} \geq 0 \cdot 5$, correlation coefficient $\geq$
0.3 for at least two variables, and communality for factor extraction $\geq 0.5$ was considered with Bartlett's test for $<0.001$. After inversely coding of negatively worded items the HBM-based statements were grouped according to the domains. Furthermore, the outcome variable was computed, if an individual is not smoking cigarette and alcohol consuming, and if an individual is taking adequate fruit/vegetable for at least five servings per day and physically active for $\geq 30$ minutes for most of the days in a week were said to have preventive behavior for these chronic disease.

A summary descriptive statistics was computed. To avoid unstable estimate, independent variables with $p$-value $\leq 0 \cdot 10$ found in the bivariate analysis were considered further candidates into the final model. A backward stepwise logistic regression analysis was applied to describe the functional relationship between demographic, knowledge and health belief domains with the outcome preventive behavior for chronic disease. For the logistic regression analysis, the dependent variable preventive behavior for the selected chronic diseases was dichotomized into able to prevent group and unable to prevent group. A point estimate of Odds Ratio (OR) with $95 \%$ confidence interval (CI) was computed to assess the strength of association between independent and dependent variable. For all statistical significant tests $p$-value $<0.05$ was used as a cut-off point.

Ethical clearance of the study was obtained from an institutional review committee of Wolkite University. Written consent was obtained from each study participants before each interview and confidentiality was guaranteed.

\section{Result}

\section{Demographic characteristics}

A total of 267 students were planned to participate in the study, out of these 257 were enrolled in the data collection, which makes a response rate of 96.3\%. Majority of the study participants 190 (73.9\%) were females. The mean age of respondent was 20.24 year $( \pm 2.42$ SD), ranging from 16 to 30 years old. The mean body mass index was 21.63 $\mathrm{kg} / \mathrm{m}^{2}( \pm 2.43 \mathrm{SD})$ and majority of the respondent 214 (83.3\%) were centrally obese. Family history of chronic disease was found in 39 (15.2\%); of these cardiovascular disease shares 17 (42.5\%), (Table 1).

\section{Predictors of preventive behaviors for chronic diseases}

Health beliefs part of the survey contains 39 items in six subscales (domains): perceived susceptibility, perceived severity, perceived benefits, perceived barriers, cue to action, and self-efficacy had an acceptable internal reliability of $0.88,0.72,0.79,0.72,0.78$, and 0.71 , respectively. A total of each subscale items were summed and dichotomized below mean and above mean to create a health belief model domain scores. Personal variables were coded individually and entered into the analysis.

Students who's their college stay $3^{\text {rd }}$ year were 2.06 time more likely to prevent chronic disease than students who's their college stay were $1^{\text {st }}$ year [OR: 2.06, 95\% CI: $(1.08,3.94)]$. Informed and/or educated about chronic disease students were 2.99 time more likely to prevent chronic disease than students who didn't educated about chronic disease [OR: $2 \cdot 99,95 \%$ CI: $(1 \cdot 64,5 \cdot 45)]$. Students who's perceived their susceptibility and severity to chronic disease were 2.97 and 2.64 time more likely to prevent chronic disease than students who didn't perceived their susceptibility and severity to chronic disease, [OR: $2 \cdot 97,95 \%$ CI: $(2 \cdot 04$ $5 \cdot 38)$, and [OR: $2 \cdot 00,95 \% \mathrm{CI}:(1 \cdot 12,3 \cdot 57)]$, respectively (Table 2$)$. 


\begin{tabular}{|c|c|c|}
\hline Variable & Frequency $(n)$ & $\begin{array}{c}\text { Percent } \\
(\%)\end{array}$ \\
\hline \multicolumn{3}{|l|}{ Sex } \\
\hline Male & 67 & $26 \cdot 1$ \\
\hline Female & 190 & $73 \cdot 9$ \\
\hline \multicolumn{3}{|l|}{ Students' stay in the college } \\
\hline $1^{\text {st }}$ year & 136 & $52 \cdot 9$ \\
\hline $2^{\text {nd }}$ year & 49 & $19 \cdot 1$ \\
\hline $3^{\text {rd }}$ year & 72 & $28 \cdot 0$ \\
\hline \multicolumn{3}{|l|}{$\mathrm{BMI}$ in $\mathbf{k g} / \mathbf{m}^{2}$} \\
\hline Underweight $(<18.5)$ & 23 & $8 \cdot 9$ \\
\hline Normal $(18 \cdot 5-24 \cdot 9)$ & 214 & $83 \cdot 3$ \\
\hline Overweight (25-29.9) & 19 & $7 \cdot 4$ \\
\hline Obese $(\geq 30)$ & 1 & $0 \cdot 4$ \\
\hline \multicolumn{3}{|c|}{ Chronic disease family history } \\
\hline Yes & 39 & $15 \cdot 2$ \\
\hline No & 218 & $37 \cdot 5$ \\
\hline \multicolumn{3}{|l|}{ Type of chronic disease } \\
\hline Cardiovascular disease & 17 & $42 \cdot 5$ \\
\hline Diabetics & 6 & $15 \cdot 0$ \\
\hline Hypertension & 15 & $37 \cdot 5$ \\
\hline Others & 2 & $5 \cdot 0$ \\
\hline
\end{tabular}

Table 1: Demographic characteristics of study participants $(n=257)$, Aman heath science college, May 2015.

\section{Discussion}

Students who have knowledge on chronic disease were developing preventive behavior for chronic disease. Since the study population was health science student, chronic disease was delivered as a course for most of them.

Students who perceived threat had have a preventive behavior for chronic disease than students who hadn't perceived threat. Where, perceived susceptibility is beliefs about the likelihood of getting a disease or condition [14]. For instance, students must believe that there is possibility of getting chronic disease if they do not practice healthy behaviors. Perception of susceptibility vary among individuals to any given illness or disease [15]. There are some people on one extreme who completely deny any possibility of getting the disease, whereas other people might admit the possibility of acquiring the disease but believe that it is not likely to happen [16]. The last groups of people are very much fearful of getting the disease but still believe that they will not acquire it. According to HBM, the more susceptible a person feels the greater likelihood of his or her taking preventive measures $[14,16]$. Perceived susceptibility has a strong cognitive component and is partly dependent on modifying factor knowledge [17], and possible social consequences" [18]. This perception also differs from person to person. Some people might perceive the disease purely from medical perspective and are mostly worried about signs and symptoms, while others might look from social perspective like adverse effects on the job, family, and relationships [16].

On the other hand some scholars explained that like perceived susceptibility, perceived severity also has strong cognitive component which depends on knowledge [17]. According to HBM, health educators need to build perceived severity by explaining the severity of the disease and personalizing those to participants [18]. For example, students might be explained that consumption of large amount of saturated fats may lead to development of chronic disease.

\begin{tabular}{|c|c|c|c|c|}
\hline \multirow[b]{2}{*}{ Variable } & \multicolumn{2}{|c|}{ Preventive behavior } & \multicolumn{2}{|c|}{ OR with $95 \% \mathrm{Cl}$} \\
\hline & $\begin{array}{l}\text { Able to } \\
\text { prevent }\end{array}$ & $\begin{array}{l}\text { Unable to } \\
\text { prevent }\end{array}$ & Crude & Adjusted \\
\hline \multicolumn{5}{|c|}{ Students' stay in the college } \\
\hline $1^{\text {st }}$ year & $34(13 \cdot 2)$ & $102(39 \cdot 7)$ & 1 & 1 \\
\hline $2^{\text {nd }}$ year & $17(6 \cdot 6)$ & $32(12 \cdot 5)$ & $\begin{array}{c}1 \cdot 48(0 \cdot 73 \\
3 \cdot 02)\end{array}$ & $1 \cdot 65(0 \cdot 76,3 \cdot 57)$ \\
\hline $3^{\text {rd }}$ year & $33(12 \cdot 8)$ & $39(15 \cdot 2)$ & $\begin{array}{c}2 \cdot 07(1 \cdot 15 \\
3 \cdot 72)\end{array}$ & $2 \cdot 06(1.08,3.94)^{\star}$ \\
\hline \multicolumn{5}{|l|}{ Knowledge } \\
\hline Uniformed & $28(10 \cdot 9)$ & $92(35 \cdot 8)$ & 1 & 1 \\
\hline Informed & $59(23 \cdot 0)$ & $78(30 \cdot 4)$ & $\begin{array}{c}2 \cdot 49(1 \cdot 45 \\
4 \cdot 27)\end{array}$ & $2 \cdot 99(1 \cdot 64,5 \cdot 45)^{\star}$ \\
\hline \multicolumn{5}{|c|}{ Perceived susceptibility } \\
\hline Not perceived & $33(12 \cdot 8)$ & $106(41 \cdot 2)$ & 1 & 1 \\
\hline Perceived & $54(21 \cdot 0)$ & $64(24 \cdot 9)$ & $\begin{array}{c}2 \cdot 71(1 \cdot 59 \\
4 \cdot 62)\end{array}$ & $2 \cdot 97(2 \cdot 04,5 \cdot 38)^{*}$ \\
\hline \multicolumn{5}{|c|}{ Perceived severity } \\
\hline Not perceived & $31(12 \cdot 1)$ & $101(39 \cdot 3)$ & 1 & 1 \\
\hline Perceived & $56(21 \cdot 8)$ & $69(26 \cdot 8)$ & $\begin{array}{c}2 \cdot 64(1 \cdot 55 \\
4 \cdot 52)\end{array}$ & $2 \cdot 00(1 \cdot 12,3 \cdot 57)^{\star}$ \\
\hline
\end{tabular}

* Statistically significant at p-value $<0.05$

Table 2: Predictors of preventive behavior for chronic non-communicable disease among healthcare students ( $n=257)$, Aman heath science college, May 2015.

When perception of susceptibility is combined with perceived severity, it results in perceived threat [14]. Previous researches shown that when there is high perceived threat, people have high chance of changing the behavior [16].

\section{Conclusion}

The variation level of preventive behavior for chronic disease was well explained by knowledge and perceived threat. Cognizant of this fact, we recommend that, integrated behavioral change communication education and information education communication emphasized on perceived treat should be strengthening to reduce the burden of lifetreating diseases.

\section{Authors' contributions}

TG was the primary researcher, conceived the study, designed, participated in data collection, conducted data analysis, result interpretation and drafted the manuscript for publication.

\section{Acknowledgements}

We extend our appreciation to the study participants for their cooperation and also we would like to thank Aman health science college dean Mr. Teklemariam Erget for his genuine support during data collection.

\section{References}

1. Fessahaye A, Abraham H, Ayalew T, Fasil Tessema, Kifle W, et al. (2012) Risk factors for chronic non-communicable diseases at Gilgel Gibe field research center, southwest Ethiopia: population based study. Ethiop J Health Sci 22.

2. WHO (2012) Non-communicable diseases prevention: time to put our act together. Global journal of medical and public health.

3. WHO (2005) Preventing chronic diseases a vital investment. Geneva.

4. Muluneh A, Haileamlak A, Tessema F, Alemseged F, Woldemichael K, et al (2012) Population based survey of chronic non-communicable diseases at Gilgel Gibe field research center, southwest Ethiopia. Ethiop J Health Sci 7-18.

5. Hlaing WW, Nath SD, Huffman FG (2007) Assessing overweight and cardiovascular risks among college students. American Journal of Health Education 38: 83-90 
Citation: Gebru T (2016) Pooled Preventive Behaviors' for Main Chronic Non-Communicable Diseases as a Double Burden of Public Health among Healthcare Students, Southwest Ethiopia. J Trop Dis 4: 198. doi:10.4172/2329-891X.1000198

6. Tassitano RM, Dumith SC, Chica DAG, Tenório MCM (2014) Aggregation of the four main risk factors to non-communicable diseases among adolescents. Rev $B$ ras epidemiol 465-478

7. Freedman DS, Dietz WH, Srinivasan SR, Berenson GS (1999) The relation of overweight to cardiovascular risk factors among children and adolescents: the bogalusa heart study. Pediatrics 103: 1175

8. Iñaki G, Fernando RA, Aurelio T, Lucía DG, Ana G, et al. (2005) Clustering of behavioural risk factors and their association with subjective health. Gac Sanit 19: $370-378$

9. Kanungsukkasem U, Minh HV, Razzaque A, Ashraf A, Juvekar S, et al. (2009) Fruit and vegetable consumption in rural adults population in INDEPTH HDSS sites in Asia. Glob Health Action 28.

10. Bich TH, Nga PTQ, Quang LN, Minh HV, Juvekar S, et al. (2009) Patterns of alcohol consumption in diverse rural populations in the Asian region. Global Health Action 2.

11. Hakimi M, Minh HV, Juvekar S, Razzaque A, Ashraf A, et al. (2009) Prevalence of physical inactivity in nine rural Health and Demographic Surveillance Systems in five Asian countries. Global Health Action.
12. Ashraf A, Quaiyum MA, Minh HV, Razzaque A, Ahmed SM, et al. (2009) Self-reported use of tobacco products in nine rural INDEPTH Health and Demographic Surveillance Systems in Asia. Global Health Action 2.

13. Razzaque A, Nahar L, Minh HV, Juvekar S, Ashraf A, et al. (2009) Social factors and overweight: evidence from nine Asian INDEPTH network sites. Global Health Action.

14. Champion VL, Skinner CS (2008) The Health Belief Model. (4th Edn), Health Behavior and Health Education: Theory, Research and Practice. San Francisco, California.

15. National Cancer Institute (2003) Theory at a Glance: A Guide for Health Promotion Practice. (2ndEdn), Department of Health and Human Services, Washington: DC, US.

16. Sharma M, Romas JA (2008) Theoretical foundations of health education and health promotion, (2ndEdn), MA: Jones and Bartlett Publishers.

17. Rosenstock I (2004) What research in motivation suggests for public health? American Journal of Public Health 50: 295-301.

18. Janz N, Champion, Strecher V (2002) The Health Belief Model. Health Behavio and Health Education. San Francisco, California. 